\title{
Kan Grupları, Gestasyonel Diyabet için Bir Risk Faktörü Müdür?
}

\author{
Is Blood Groups A Risk Factor for Gestatıonal Diabetes? \\ Mahmut Apaydın ${ }^{1}$, Özden Özdemir Başer ${ }^{1}$, Taner Demirci² ${ }^{2}$ Ceyhun Varım³ \\ ${ }^{1}$ Endokrinoloji ve Metabolizma Kliniği, Yozgat Şehir Hastanesi, Yozgat, Türkiye \\ ${ }^{2}$ Endokrinoloji ve Metabolizma Bilim Dalı, İ̧ Hastalıkları Anabilim Dalı, Sakarya \\ ${ }^{3} \dot{I}_{c ̧}$ Hastalıkları Anabilim Dalı, Sakarya Üniversitesi Tip Fakültesi, Sakarya \\ Yazıșma Adresi / Correspondence: \\ Ceyhun Varım
Adnan Menderes caddesi, Sağlık Sokak, No: 195-54000, Adapazarı/Sakarya
T: +902642552106 E-mail : ceyhunvarim@yahoo.com \\ Geliş Tarihi / Received : 12.2.2020 Kabul Tarihi / Accepted : 01.05.2020 \\ Orcid : \\ Mahmut Apaydın https://orcid.org/ 0000-0002-7533-7084 \\ Özden Özdemir Bașer https://orcid.org/ 0000-0001-8368-3182 \\ Taner Demirci https://orcid.org/ 0000-0002-9579-4530 \\ Ceyhun Varım https://orcid.org/ 0000-0002-8369-0857 \\ ( Sakarya Tip Dergisi / Sakarya Med J 2020, 10(2):205-209) DOI: 10.31832/smj.688662
}

\footnotetext{
Öz

Amaç Gestasyonel Diyabetes Mellitus (GDM) sıklı̆ı̆ giderek artan ve perinatal komplikasyonlar ile ilișkisi gösterilmiș klinik durumdur. Bu durumun kan grupları ile arasındaki ilişki kesin olarak belli değildir. Biz bu çalışmada kendi coğrafi bölgemiz olan Yozgat șehrinde GDM ile kan grupları arasındaki ilişkiyi değerlendirmeyi amaçladık.

Gereç ve Retrospektif olan çalıșmamıza 1873 gebe kadın alınmıștır. Ocak 2018- Aralık 2019 tarihleri arasında kliniğimize başvuran, 24-28. gebelik haftalarında olan hastaların

Yöntem dosyaları incelenmiştir. Hastaların dosyalarından OGTT (Oral Glukoz Tolerans Testi) sonuçları ve kan grupları bulunmuștur. OGTT sonuçları ile kan grubu arasındaki iliş̧ki incelenmiștir.

Bulgular OGTT sonucuna göre 326 (\%17,40, yas: 31,40+5,70) olgu GDM tanısı alırken 1547 (\% 82,60 yas: 29+5,10) kişi normal (kontrol) olarak saptanmıștır. GDM ve kontrol grubu için kan grupları sırasılyla A grubu \%41,70- \%45, B grubu \%19,90-15,80, AB grubu \%4,30-7,20 ve O grubu \%34-32 olarak tespit edilmiştir. Gruplar arasında istatistiksel olarak anlamlı düzeyde fark saptanmamıștır. Kontrol ve GDM grubunda Rh faktör pozitifliği yüzdesi sırasıyla $\% 88,10$ ve $\% 89,60$ olup gruplar arasında anlamlı fark saptanmamıștır.

Sonuç Non-AB kan gruplarına sahip gebe kadınların, anlamlı fark saptanmamakla birlikte, artmıș GDM riskine sahip olduklarını gözlemledik (\%7,20 ve \%4,30). Tespit ettiğimiz kan grubu dağılımları genel popülasyonla benzer olup coğrafyamıza özgü farklılıklar da içermemektedir.

Anahtar Kan gruplarl; gebelik; gestasyonel diyabet.

Kelimeler

$\ddot{O} z$

Objective Gestational Diabetes Mellitus (GDM) is a clinical condition with increasing frequency and has been shown to be associated with perinatal complications. The relationship between GDM and blood groups is unclear. In this study, we aimed to evaluate the relationship between GDM and blood groups in Yozgat, which is our own geographical region.

Materials

In our retrospective study, 1873 patient were included. The data of 1873 pregnant women who applied to our clinic between January 2018 and December 2019 and who are at gestational weeks between 24-28 were examined. OGTT (Oral Glucose Tolerance Test) test results and blood groups were recorded and analyzed.

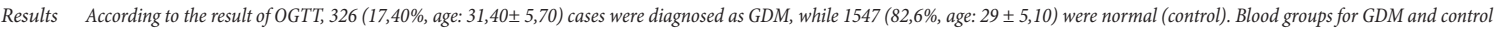
groups were defined as group A 41,70-45\%, group B 19,90-15,80\%, group AB 4,30-7,20\% and group 0 34-32\%, respectively. There was no statistically significant difference between the groups. Rh positivity percentages in the control and GDM groups were $88,10 \%$ and $89,60 \%$, respectively. There was no statistically significant difference between the groups.

Conclusion We observed that pregnant women with non-AB blood group had an increased risk of GDM, but this difference was not significant (7,20\% vs. 4,30\%). The blood group distributions that we detected are similar to the general population and do not include specific differences to our geography.

Keywords Blood groups; pregnancy; gestational diabetes mellitus.
} 


\section{GIIRIș}

Gestasyonel diabetes mellitus (GDM); fetal makrozominin, doğum komplikasyonlarının ve annede doğum sonrası tip 2 dm gelişme riskinin artışı ile karakterize, gebelik döneminde görülen en sık endokrinolojik hastalıktır. ${ }^{1-3}$ GDM prevalansı son 10 yılda tüm dünyada artış göstermektedir. Prevalansı baz alınan tanı kriterlerinden, farklı tarama testlerinin uygulanışından, popülasyon çeşitliliğinden ve sosyoekonomik nedenlere bağlı değişkenlik göstermektedir. Bu nedenle çoğu çalışmada farklılık göstererek çok geniş aralıkta saptanabilmektedir. Öne çıkan çalışmalarda GDM prevalansı \%8,20 ve \%13,20 olarak verilmektedir. ${ }^{4-5}$ Ülkemizde yayınlanan bir derlemede ise GDM prevalansı \%7,70 (\%1,90- 27,90) olarak verilmiştir. ${ }^{6}$

Kan grupları, 9. kromozomun uzun kolunda yer alan (9q34) ABO geni tarafından düzenlenmektedir. A ve B varyant allelleri tarafından üretilen $A$ ve $B$ antijenleri varlığına göre kan grupları çeşitlilik göstermektedir.7 ABO kan grupları ile Rh faktörün kardiyovasküler hastalıklar, maligniteler, inme vb. ile ilişkisinin incelendiği çok sayıda çalışma mevcut olup bazı kan gruplarında hastalık riskinin $\operatorname{arttı̆̆}_{1}$ saptanmıştır. ${ }^{8-11}$

Tip 2 Diyabetes Mellitus ile kan grubu ilişkisinin incelendiği çeşitli çalışmalar mevcuttur ancak sonuçlar değişkenlik göstermektedir. Bunun nedeni olarak etnisite, çalışmanın yapıldığı popülasyon ve alınan hasta sayılarının farklılığı sayılabilir. ${ }^{12-13} \mathrm{ABO}$ kan gruplarının diyabet gelişimindeki rolü ise halen tartışmalıdır. Çünkü ABO gen lokusunda varyasyonlara neden olduğu gösterilen Blood Soluble E-selektin (sE-selektin), Soluble İntrasellüler Hücre Adezyon Molekülü-1 (sICAM-1), Tümör Nekrozis Faktör- alfa reseptör-2 (TNF-alfa R2) gibi bazı biyobelirteçlerin ABO kan grupları ile DM arasındaki ilişkiye aracılık edebilecekleri saptanmıştır. ${ }^{14-16}$ ABO genotipinin, glukoz metabolizması ve enerji dengesi üzerine olan etkilerinin yanında düşük düzeyde inflamasyona yol açarak obezite ve DM (Diabetes Mellitus) etyopatogenezinde rol aldığı düşünülen intestinal mikrobiatanın kompozisyonundan sorumlu olan en önemli genetik belirteçlerden biri olduğunu destekleyen çalışmalar mevcuttur. $^{15,17-18}$

Tip 2 Diyabetes Mellitus etiyopatogenezinde yer alan kalıtsal pankreas adacık hücre disfonksiyonu ve/ veya beta hücre anormalliklerinin GDM etiyopatogenezinde de rol oynayabileceği gösterilmiştir. ${ }^{19}$ GDM ile ABO kan grupları arasındaki ilişkiyi inceleyen sınırlı sayıda çalışma vardır. ${ }^{20-23}$ Çalışmamızı, spesifik kan grupları ile GDM arasındaki ilişkiyi incelemek ve Orta-Anadolu'yu temsilen Yozgat şehrine ait olası farklılıkları ortaya çıkarmayı amaçladık.

\section{GEREÇ ve YÖNTEMLER}

Çalışmamız, Bozok Üniveritesi Klinik Araştırmalar Etik Kurulu tarafindan değerlendirilmiş ve 2017 KAEK_189_2019.12.25_06 karar numarası ile onaylanmış ve Helsinki İlkeler Deklerasyonuna (www.wma.net/e/policy/b3.htm) uyularak gerçekleştirilmiştir. Çalışmamızda 1 Ocak 2018- 31 Aralık 2019 yılları arasında polikliniğimize başvuran ve oral glukoz tolerans testi (OGTT) yapılmış 1873 gebe kadının sonuçları retrospektif olarak taranmıştır. Çalışmamız retrospektif vaka-kontrol çalışmasıdır. Tüm hastalardan OGTT için onam alınmıştır. GDM taraması 24-28. gebelik haftaları arasında tek basamaklı (75gr OGTT) veya iki basamaklı (50gr-100gr OGTT) testler ile yapılmış olup her iki yöntemde en az 8 saat açlık sonrası uygulanmıştır. Hastalara 100 gr OGTT ve 75 gr OGTT test öncesi en az 150gr/gün karbonhidrat içeren üç günlük test öncesi diyeti verilmiştir. 50 gr glukoz yükleme testinde 1 . saat plazma glukozu olarak eşik değeri 140 mg/dl alınmış olup bu değeri aşan gebelerde yapılan 100 gr OGTT testinde ise Carpenter ve Caustan kriterleri (2 anormal sonuç tanı için yeterlidir. Normal plazma glukoz değerleri; açlık $<95 \mathrm{mg} / \mathrm{dl}$; 1 . saat $<180 \mathrm{mg} / \mathrm{dl} ; 2$.saat $<155 \mathrm{mg} / \mathrm{dl}$ ve 3 . saat $<140 \mathrm{mg} / \mathrm{dl}$ ) kullanılmıştır. Tek basamaklı tanı testi olarak yapılan 75 gr OGTT de ise 2008 HAPO (Hipreglisemia Advers Pregnancy Outcomes) tanı kriterleri (tek anormal sonuç tanı için yeterlidir. Açlık plazma glukozu $\geq 92 \mathrm{mg} / \mathrm{dl}$; 
1.saat $\geq 180 \mathrm{mg} / \mathrm{dl} ; 2 . s a a t \geq 153 \mathrm{mg} / \mathrm{dl}$ ) kullanılmıştır. Test sonuçlarına göre olgular GDM olan ve olmayan (normal) şeklinde iki gruba ayrılmıştır.

ABO ve Rh kan gruplar1 ya Dia-Gast (BP-9-59374 100S France) kiti kullanılarak tüp aglütinasyon yöntemi ile ya da DiaMed (1785) GmbH, Cressier FR Switzerland kiti kullanılarak jel sentrifügasyon yöntemi ile tanımlanmıştır.

\section{İstatiksel analiz}

İstatiksel analizler SPPSS 22.0 aglı program kullanılarak yapıldı. (StatisticalPackage for Social Science, SPSS inc. Chicago IL, USA ${ }^{\circledR}$ ). Gestasyonel diyabet olan hasta ve olmayan sağlıklı kontrol olgularında Rh antijenleri ve spesifik kan grupları çapraz tablolar kullanılarak verildi. Tanımlayıcı istatistik yöntemleri ile sıklıklar yüzdeler ile ifade edildi. Gruplar arasında bu sıklıklar bakımından fark bulunup bulunmadığ 1 yerine göre Ki-kare ya da Fisher testleri (hücrelerde gözlenen değerlerin Ki-kare testi ile varsayımlarını sağlamadığı durumda) kullanılarak karşılaştırıldı. P değerinin 0,05'in altında olduğu durumlar istatiksel olarak anlamlı sonuçlar şeklinde değerlendirildi.

\section{BULGULAR}

Çalışmaya 24-28. gestasyonel haftalarda OGTT yapılan 1873 hasta alınmıştır. OGTT sonucuna göre $326(\% 17,40)$ hasta GDM tanısı alırken $1547(\% 82,60)$ olguda normal sonuç elde edilmiştir. Normal sonuç elde edilen olgular kontrol grubu olarak kabul edilmiştir. Yaş dağılımı 18-47 yıl arasında değişmekte olup yaş ortalaması kontrol grubunda $29 \pm 5,10$ yil ve GDM grubunda $31,40 \pm 5,70$ yil olarak saptanmıştır.

Kan gruplarına göre değerlendirildiğinde GDM ve kontrol grubu için sırasiyla A grubu 41,70-45\%, B grubu \%19,90$15,80 \%$, AB grubu $\% 4,30-7,20 \%$ ve O grubu $\% 34-32 \%$ olarak tespit edilmiştir (tablo-1). Gruplar arasında istatiksel olarak anlamlı düzeyde fark saptanmamıştır. Rh antijenlerine göre değerlendirildiğinde de gruplar arasında fark gözlenmemiştir ( $\mathrm{p}=0,454$; tablo-2). Olgular spesifik olarak alt grupları ile birlikte incelendiğinde de anlamlı düzeyde fark tespit edilmemiştir ( $p=0,066)$. Tüm kan grubu dağılımları Tablo-3'de özetlenmiştir.

Tablo 1: AB0 antijenlerine göre GDM ve Kontrol gruplarının dağılımı.

\begin{tabular}{|l|c|c|c|}
\hline Kan Grubu & $\begin{array}{c}\text { Gestasyonel } \\
\text { Diyabet (n) }\end{array}$ & Kontrol (n) & \multirow{2}{*}{ P Değeri } \\
\cline { 1 - 3 } $\mathrm{A}$ & $136(\% 41,70)$ & $696(\% 45,00)$ & \\
\cline { 1 - 3 } $\mathrm{B}$ & $65(\% 19,90)$ & $245(\% 15,80)$ & \multirow{2}{*}{0,069} \\
\cline { 1 - 3 } $\mathrm{AB}$ & $14(\% 4,30)$ & $111(\% 7,20)$ & \\
\cline { 1 - 3 } 0 & $111(\% 34)$ & $495(\% 32)$ & \\
\hline TOPLAM & $326(\% 17,40)$ & $1547(\% 82,60)$ & \\
\hline
\end{tabular}

Tablo 2: Rh antijenlerine göre GDM ve Kontrol gruplarının dağılımı.

\begin{tabular}{|l|c|c|c|}
\hline & Rh pozitif (n) & Rh negative (n) & P Değeri \\
\cline { 1 - 3 } $\begin{array}{l}\text { Kontrol (n: } \\
1547)\end{array}$ & $1363(\% 88,10)$ & $184(\% 11,90)$ & \\
\cline { 1 - 3 } $\begin{array}{l}\text { GDM (n: } \\
\text { 326) }\end{array}$ & $292(\% 89,60)$ & $34(\% 10,40)$ & \\
\hline \multicolumn{2}{|l|}{ GDM: Gestasyonel Diabetes Mellitus } \\
\hline
\end{tabular}

Tablo 3: ABO ve Rh Subgruplarına göre GDM ve Kontrol gruplarının dağılımı.

\begin{tabular}{|c|c|c|c|c|}
\hline & & GDM (n) & Kontrol (n) & \\
\hline \multirow{4}{*}{$\mathrm{Rh}(+)$} & $\mathrm{A}$ & $118(\% 36,20)$ & $621(\% 40,10)$ & \multirow{8}{*}{$\mathrm{P}=0,066$} \\
\hline & B & $59(\% 18,10)$ & $212(\% 13,70)$ & \\
\hline & $\mathrm{AB}$ & $11 \quad(\% 3,40)$ & $98(\% 6,30)$ & \\
\hline & 0 & $104(\% 31,90)$ & $432(\% 27,90)$ & \\
\hline \multirow{4}{*}{$\mathrm{Rh}(-)$} & A & $18(\% 5,50)$ & $33(\% 4,80)$ & \\
\hline & B & $6(\% 1,80)$ & $33(\% 2,10)$ & \\
\hline & $\mathrm{AB}$ & $3(\% 0,90)$ & $13(\% 0,80)$ & \\
\hline & 0 & $7(\% 2,10)$ & $63(\% 4,10)$ & \\
\hline
\end{tabular}

\section{TARTIŞMA}

ABO kan grubu dağılımı başlıca coğrafi bölge ve etnik köken olmak üzere çeşitli nedenlerle farklılık göstermektedir. Ülkemiz genelinde kadın ve erkek popülasyonunda ABO kan grubu dağılımı ile ilgili Ergün ve arkadaşlarının yaptığı çalışmada A, 0, B ve AB sırasıyla \%42,80, \%32,60, $\% 16,40$, \%8 ve Rh pozitiflik oranı ise \%88,50 olarak saptanmıştır. ${ }^{24}$ Kader ve arkadaşlarının Yozgat ilinde kan gru- 
bu dağılımını inceledikleri çalışmada ise $A, 0, B$ ve $A B$ sirasiyla $\% 44,30, \% 31,70, \% 15,90, \% 8,10$ ve Rh pozitiflik oranı ise \%88,00' dir. ${ }^{25}$ Bizim çalışmamızda ise kontrol grubunda kan grubu dağılımı A \%45, $0 \% 32$, B \%15,80, $\mathrm{AB} \% 7,20$ ve $\mathrm{Rh}$ pozitiflik oranı ise $\% 88,10$ olarak tespit edilmiştir. Diğer iki çalışmadan farklı olarak çalışmamızda, kontrol grubunu GDM saptanmayan gebe kadınlar oluşturmaktadır. Sonuçlarımız diğer iki çalışma sonuçları ile karşılaştırıldığında $\mathrm{ABO}$ kan gruplarının ve Rh faktörün dağılımları benzerdi ( $A B 0$ için $p=0,069$ ve $R h$ için $\mathrm{p}=0,454)$.

GDM prevalansı, tip 2 DM ve obezite sıklığının artışına paralel olarak tüm dünyada artmaktadır. GDM patofizyolojisi henüz tam olarak netleşmemiştir. ABO kan grupları ile GDM ilişkisini inceleyen az sayıda çalışma mevcuttur ve çalışmalar incelendiğinde farklı sonuçların elde edildiği görülmektedir.

Çalışmamızda GDM grubundaki AB kan grubuna sahip hasta yüzdesi, kontrol grubu ile karşılaştırıldığında daha düşük bulunmuştur $(\% 4,30$ ve $\% 7,20)$ ancak fark istatistiki olarak anlamlı değildir $(\mathrm{p}=0,06)$. Benzer bir sonuca Zhang ve arkadaşlarının çalışmasında ulaşılmış olup non-AB kan grubundaki GDM riski $\mathrm{AB}$ kan grubuna göre istatistiksel olarak anlamlı derecede yüksek bulunmuştur $(\mathrm{OR}=1,44){ }^{21}$ $\mathrm{Bu}$ sonuçlardan farklı olarak Karagöz ve arkadaşlarının çalışmasında $\mathrm{AB}$ kan grubuna sahip olguların oranı GDM grubunda anlamlı olarak yüksek tespit edilmiştir $(\mathrm{p}=0,029)$. Aynı çalışmada doğum sonrası annede kalıcı DM gelişme sıklığı O kan grubunda anlamlı olarak fazla bulunmuştur $(\mathrm{p}=0,001) .20$ Yakın zamanda yayınlanan Sapanont ve arkadaşlarının çalışmasında 0 kan grubu ile diğer kan grupları (non-0) karşılaştırıldığında 0 kan grubunda GDM riskinin anlamlı olarak artmış olduğu saptanmıştır (OR 1.51, P=.020), ancak ABO kan gruplarının GDM ve kontrol grubundaki dağılımı arasında anlamlı fark bulunmamıştır. ${ }^{23} \mathrm{Bu}$ sonuçlar bize ABO kan grupları ile GDM riski arasındaki ilişkinin farklı populasyonlarda değişkenlik gösterebileceğini kanıtlamaktadır.
Rh faktör ve DM gelişimi üzerine az sayıda çalı̧̧ma mevcut olup farklı sonuçlar sonuçlar elde edilmiştir. ${ }^{26-27}$ Çalışmamızda kontrol ve GDM grubunda Rh faktör pozitifliği yüzdesi sırasıyla $\% 88,10$ ve $\% 89,60$ olup gruplar arasında anlamlı fark saptanmamıştır. Sonuçlarımız Zhang ve arkadaşlarının çalışması ile benzerdir. ${ }^{21}$

Çalışmamızın kısıtlı yönleri arasında tek merkezli bir çalışma olması ve GDM tanısında iki basamak ve tek basamak yaklaşımlarının birlikte kullanılması gösterilebilir. Obezite de GDM için önemli bir risk faktörüdür. Çalışmamızda hastalarda BMI bakılmaması da çalışmamızın önemli bir kısıtlı yönüdür. Bir diğer zayıf yönü ise demografik verilerinin kayıt altına alınmamasıdır.

Biz bu çalışmada non- $\mathrm{AB}$ kan gruplarına sahip gebe kadınların, anlamlı bir fark saptanmamakla birlikte, artmış GDM riskine sahip olduklarını gözlemledik. Non-AB kan gruplarına sahip kadınların, diyabet gelişimi için ek risk faktörlerine de sahiplerse, GDM riski açısından gebelik öncesi veya erken gebelik haftalarında bilgilendirilmeleri gerektiği çıkarımını yapabiliriz. GDM de spesifik kan grupları arasındaki ilişkiyi net bir şekilde ortaya koymak için çok merkezli, geniş coğrafi dağılımı temsil eden daha geniş hasta popülasyonlarının alındığı çalışmalara ihtiyaç vardır.

Çalışmamız, Bozok Üniveritesi Klinik Araştırmalar Etik Kurulu tarafından değerlendirilmiş ve 2017_ KAEK_189_2019.12.25_06 karar numarası ile onaylanmış ve Helsinki İlkeler Deklerasyonuna (www.wma. net/e/policy/b3.htm) uyularak gerçekleştirilmiştir. 
Sakarya Tip Dergisi 2020;10(2):205-209

APAYDIN ve Ark., Kan Grupları, Gestasyonel Diyabet için Bir Risk Faktörü Müdür?

\section{Kaynaklar}

1. American Diabetes, Assoc.14. Management of Diabetes in Pregnancy: Standards of Medical Care in Diabetes-2019. Diabetes Care 2019; 2(Suppl 1):165-172.

2. Metzger BE., et al., Hyperglycemia and adverse pregnancy outcomes. N Engl J Med 2008; 358(19):1991-2002.

3. Bellamy L., et al., Type 2 diabetes mellitus after gestational diabetes: a systematic review and meta-analysis. Lancet 2009; 373(9677):1773-1779.

4. Melchior, H., Kurch-Bek D., Mund M., The Prevalence of Gestational Diabetes. Dtsch Arztebl Int 2017; 114(24): p. 412-418.

5. Zhou T., et al., Prevalence and Trends in Gestational Diabetes Mellitus among Women in the United States, 2006-2016; Diabetes 2018. 67-1:121-OR.

6. Karacam, Z. and Celik D., The prevalence and risk factors of gestational diabetes mellitus in Turkey: a systematic review and meta-analysis. J Matern Fetal Neonatal Med 2019;1-11.

7. Reid, M.E. and Mohandas N., Red blood cell blood group antigens: structure and function. Semin Hematol 2004; 41(2):93-117.

8. He, M., et al., ABO blood group and risk of coronary heart disease in two prospective cohort studies. Arterioscler Thromb Vasc Biol 2012; 32(9):2314-2320.

9. Song, Q., et al., The ABO Blood Group is an Independent Prognostic Factor in Patients with Ovarian Cancer. J Cancer 2019; 10(26):6754-6760.

10. Zakai, N.A., et al., ABO blood type and stroke risk: the REasons for Geographic And Racial Differences in Stroke Study. J Thromb Haemost 2014; 12(4):564-570.

11. Yu, H., et al., Association of ABO Blood Groups and Risk of Gastric Cancer. Scand J Surg, 2019;145

12. Kamil, M., Al-Jamal AH., and Yusoff NM., Association of ABO blood groups with diabetes mellitus. Libyan J Med 2010;5.

13. Fagherazzi, G., et al., ABO and Rhesus blood groups and risk of type 2 diabetes: evidence from the large E3N cohort study. Diabetologia 2015; 58(3):519-522.

14. Pare, G., et al., Novel association of ABO histo-blood group antigen with soluble ICAM1: results of a genome-wide association study of 6,578 women. PLoS Genet, 2008; 4(7): e1000118.
15. Paterson, A.D., et al., Genome-wide association identifies the ABO blood group as a major locus associated with serum levels of soluble E-selectin. Arterioscler Thromb Vasc Biol 2009: 29(11): 1958-1967.

16. Barbalic, $M$., et al., Large-scale genomic studies reveal central role of $A B O$ in $s P$-selectin and sICAM-1 levels. Hum Mol Genet 2010; 19(9):1863-1872.

17. Abenavoli, L., et al., Gut Microbiota and Obesity: A Role for Probiotics. Nutrients 2019; 11(11).

18. Sanmiguel, C., Gupta A., and Mayer EA., Gut Microbiome and Obesity: A Plausible Explanation for Obesity. Curr Obes Rep 2015; 4(2):250-261.

19. Zhang, C., et al., Genetic variants and the risk of gestational diabetes mellitus: a systematic review. Hum Reprod Update 2013; 19(4):376-390.

20. Karagoz, H., et al., The role of blood groups in the development of diabetes mellitus after gestational diabetes mellitus. Ther Clin Risk Manag 2015; 11: p. 1613-1617.

21. Zhang, C., et al., Blood group AB is protective factor for gestational diabetes mellitus: a prospective population-based study in Tianjin, China. Diabetes Metab Res Rev 2015; 31(6):627-637.

22. Phaloprakarn, C. and Tangjitgamol S., Maternal ABO blood group and adverse pregnancy outcomes. J Perinatol 2013; 33(2):107-111.

23. Sapanont, K., P. Sunsaneevithayakul, and D. Boriboonhirunsarn, Relationship between ABO blood group and gestational diabetes mellitus. J Matern Fetal Neonatal Med 2019; 1-5.

24. Ergün A, YS., Türkiye Genelinde ABO kan grupları ve Rh faktörün dağllımı. Ankara Üniversitesi Tip Fakültesi Mecmuası 1993; 46(3): 527-533.

25. Çiğdem Kader, S.Y., Doğan B., Ptnarbașll M., İlanbey B., Erbay A., ABO and Rh Blood Groups Distribution in Yozgat City, Turkey. J Clin Exp Invest 2014; 5(2):169-172.

26. Okon, U.A., et al., The relative incidence of diabetes mellitus in ABO/Rhesus blood groups in South-Eastern Nigeria. Niger J Physiol Sc 2008; 23(1-2):1-3.

27. Sidhu, L.S., Malhotra P., and Singh SP., ABO and Rh blood groups in diabetes mellitus. Anthropol Anz 1988; 46(3): 269-275. 